\title{
Ecologia e Identidade Local: Considerações sobre o Cittaslow e suas estratégias para um Desenvolvimento Urbano Sustentável.
}

\author{
Ecology and Local Identity: Considerations on the Cittaslow and your strategies \\ for a Sustainable Urban Development.
}

La Ecología y la Identidad Local: Consideraciones sobre el Cittaslow y sus estrategias para el Desarrollo Urbano Sostenible.

\section{Rubens Moreira Rodrigues de Carvalho} Doutorando, PPGAU/UFF, Brasil Mestre em Arquitetura e Urbanismo, PPGAU/UFF, Brasil rubens.moreira.cavralho@gmail.com 


\section{RESUMO}

O presente artigo traz considerações de uma tese de doutorado em andamento. O estudo, que se desenvolve no campo da arquitetura e do urbanismo, com ênfase para a produção e a gestão do espaço urbano, tem a premissa de esclarecer o que é e a que se destina a iniciativa Cittaslow - criada na Itália, em 1999, com base nos ideais do Slow Food, e hoje presente em 30 países no mundo. Os dados e os argumentos aqui dispostos estão pautados na pesquisa que vem sendo realizada desde 2013 sobre o tema e em recente viagem de estudos ao país de origem do Cittaslow, realizada entre os meses de abril e julho de 2016. O objetivo do artigo é apresentar uma análise do Cittaslow segundo a ótica do urbanismo ecológico, com base em sua história, sua filosofia e suas políticas. A intenção é destacar o papel da identidade e da ecologia no debate sobre a sustentabilidade urbana, contribuindo para uma maior divulgação e um aprofundamento da filosofia Cittaslow no Brasil.

Palavras-chave: Cittaslow. Identidade Local. Urbanismo Ecológico.

\section{ABSTRACT}

This paper presents considerations of a PhD research in progress. The study develops in the field of urban planning, with emphasis on the production and management of urban space, and aims to clarify what is the Cittaslow initiative - established in Italy in 1999, based on the ideals of Slow Food, and now present in 30 countries worldwide. The arguments presented here are guided by the research that has been conducted since 2013 and in a recent study tour to the Cittaslow origins, between April and July 2016. The intention of this article is analyze the Cittaslow initiative from the perspective of ecological urbanism, based on its history, its philosophy and its policies. We intend, with this, highlight the role of identity and ecology in the urban sustainability, contributing to greater awareness of Cittaslow philosophy in Brazil.

Keywords: Cittaslow. Local identity. Ecological Urbanism.

\section{RESUMEN}

Esta ponencia presenta consideraciones de una investigación de doctorado en curso. El estudio se desarrolla en el campo de la planificación urbana, con énfasis en la producción y gestión del espacio urbano, y tiene por objeto aclarar lo que es la iniciativa Cittaslow - establecida en Italia en 1999, basado en los ideales de Slow Food, y ahora presente en 30 países de todo el mundo. Los argumentos presentados aquí son guiados por la investigación que se ha llevado a cabo desde 2013 y en un reciente viaje de estudio a los orígenes de Cittaslow, entre abril y julio de 2016. La intención de este artículo es analizar la iniciativa Cittaslow desde la perspectiva del urbanismo ecológico, basadas en su historia, su filosofía y sus políticas. Pretendemos, con este, resaltar el papel de la identidad y de la ecología en la sostenibilidad urbana, de modo que contribuya a una mayor conciencia de la filosofía Cittaslow en Brasil.

Palabras clave: Cittaslow. La identidad local. Urbanismo ecológico. 


\section{INTRODUÇÃO}

It is time to employ one of the greatest human talents, the ability to manipulate the environment, to transform an environment that has become hostile to life itself into a humane habitat which sustains life and nurtures growth, both personal and collective (SPIRN, 1984, p.275).

O urbanismo está no centro de um debate importante sobre a sustentabilidade das cidades e as condições de vida das sociedades contemporâneas. A urbanização é um fenômeno com enormes implicações sociais, econômicas, culturais e ambientais, com interferências na gestão dos recursos naturais e na manutenção dos ecossistemas do planeta. Os últimos dois séculos da história humana ficaram marcados por intensos avanços nas áreas técnicas e científicas e por significativas mudanças na forma como os homens interagem com o ambiente e no modo como as sociedades percebem os efeitos e os impactos dessa interação.

Ao longo desse período, as populações urbanas cresceram não apenas em número, mas principalmente em proporção. Transitamos de um sistema orientado pela produção (e para a produtividade) para outro regido pelo consumo, e de um contexto predominantemente rural para outro predominantemente urbano. Estimativas da Unicef (2012) indicam que hoje cerca de $80 \%$ da população da América Latina vive em áreas urbanas - ainda que nesse percentual encontre-se uma parcela significativa de áreas "intermediárias", entre o rural e o urbano, às quais José Eli da Veiga (2002) define como "rurbanas".

Muitas dessas áreas urbanas e "rurbanas", no entanto, são carentes de serviços essenciais e não possuem infraestrutura adequada, o que amplifica os conflitos associados à intensificação da ocupação urbana. Dados da ONU (2012) indicam que, apesar de ocuparem apenas $2 \%$ da massa de terra no mundo, as cidades utilizam cerca de $75 \%$ dos recursos naturais do planeta, colocando em risco a integridade e a diversidade biológica de nossos ecossistemas. Essa degradação ambiental, por sua vez, pode ter efeitos imprevisíveis na economia, na saúde e na funcionalidade das cidades e no bem-estar de seus habitantes, o que eleva a importância e a urgência de alternativas ecológicas para a ocupação urbana.

Nesse contexto, pelo menos dois aspectos carecem de maior aprofundamento, no sentido de ajudar as sociedades a encontrar saídas para os desafios do século XXI. O primeiro se refere à homogeneização da identidade urbana, em virtude de processos como a globalização e a industrialização, e o segundo diz respeito à sustentabilidade das cidades, em função de suas demandas por recursos naturais, do consumo não consciente desses recursos e dos impactos ambientais ligados ao crescimento das áreas urbanas.

Estes dois aspectos estão vinculados, ainda, a um terceiro, relativo ao bem-estar físico e social dos habitantes das cidades. $O$ bem-estar é um conceito subjetivo e abrangente, mas muito ligado à saúde do ambiente urbano e à qualidade dos serviços e da infraestrutura da cidade. Nesse sentido, alternativas aos problemas do presente ou do futuro, que visam corroborar a 
formação de ambiências mais qualificadas e agradáveis, adequadas tanto às necessidades da sociedade, quanto aos limites do ambiente, precisam considerar o bem-estar na equação.

O Cittaslow, enquanto rede organizada de pequenas cidades, reúne todos esses aspectos em planos urbanos regionais, com foco nos ativos da identidade local e nas singularidades, isto é, nas características próprias de cada localidade ou microrregião (RADSTROM, 2011). É através de sua rede que o Cittaslow promove suas estratégias e ideais, motivando pequenas cidades a planejar seu futuro, sem abrir mão das inovações e dos benefícios da modernidade, mas com respeito ao passado, à natureza, à identidade e aos demais valores únicos do lugar.

o Cittaslow aborda a cidade e sua identidade a partir de um prisma ecológico - e é sobre essa relação que iremos nos debruçar a seguir. Acreditamos que a cidade pode ter papel-chave na solução de muitos desafios mundiais, liderando o esverdeamento da economia mundial, em função de sua eficiência nos consumos de energia, água e outros recursos naturais, de saídas inteligentes para os transportes e a mobilidade urbana, da mitigação dos impactos gerais das construções e do reaproveitamento dos resíduos, dentre outras ações.

\title{
ORIGEM E ABRANGÊNCIA DO CITTASLOW
}

\begin{abstract}
Quando há 15 atrás nós sonhamos em contribuir para a melhoria do planeta, [...] estávamos no meio da chamada "e-economy" e do boom financeiro especulativo mundial que deveria abrir as portas para um novo século de prosperidade e consumo sempre crescente para todos, sem qualquer esforço. Os primeiros dez anos do século XXI trouxeram todos de volta à realidade. [...] Nosso argumento não é uma apologia ao passado, nós damos boas-vindas para as novas tecnologias que melhoram a preservação ambiental, que aumentam a dignidade do trabalho e a eficiência dos sistemas e dos serviços sociais. Mas as comunidades Cittaslow de todo o mundo são um testemunho vivo e ativo de que é importante compreender o senso de limite a assistir, sim, a globalização positiva, mas também o desenvolvimento autocentrado. Isso não significa voltar atrás, mas, ao contrário, sugere percorrer o caminho da economia durável e não efêmera, da justiça social, da produção e do consumo justo e equilibrado, da solidariedade e da responsabilidade compartilhada, sem retóricas e falsos idealismos, mas com ideias concretas e pragmatismo (CITTASLOW, 2014, [Livreto de Divulgação]).
\end{abstract}

O Cittaslow foi fundado em 1999, na cidade de Orvieto, na Itália, em encontro organizado por Paolo Saturnini, então prefeito da pequena e notória cidade de Greve in Chianti, situada no coração da Toscana, com prefeitos de outras três cidades de características análogas: Stefano Cimicchi (de Orvieto, na Úmbria), Francesca Guida (de Bra, no Piemonte) e Domenico Marrone (de Positano, na Campânia). Além destes, participou também o fundador e atual presidente do Slow Food, o jornalista Carlo Petrini, com contribuições significativas para a fundamentação e para a filosofia do Cittaslow (CITTASLOW, 2015). 
Desde a sua fundação, o Cittaslow vem se expandido de maneira significativa, traspassando, inclusive, as bordas do território italiano. Atualmente a iniciativa conta com uma rede de 225 cidades-lentas, situadas em 30 países do mundo, segundo a última lista divulgada em junho de 2016 (CITTASLOW, 2016). Grande parte dessas cidades se encontra na Europa ou mesmo na própria Itália, que abriga cerca de um terço do número total. No entanto, existem exemplos de cidades-lentas também na América do Norte, na Ásia, na África e na Oceania.

Recentemente, a pequena cidade de Pijao (Quindío), uma comunidade com cerca de seis mil habitantes da Colômbia, ganhou o título de primeira (e, até o momento, única) cidade-lenta da América Latina. Uma conquista associada à proteção das tradições e da arquitetura típica de uma comunidade do eixo cafeeiro local (HINCAPIÉ, 2014).

Tabela 01: Crescimento do Cittaslow.

\begin{tabular}{llll}
\hline ANO & No. CIDADES-LENTAS & CONCENTRAÇÃO & FONTE \\
\hline 1999 & 04 cidades (Fundação) & Todas na Itália & (MAYER; KNOX, 2006) \\
\hline 2000 & Aprox. 20 cidades & Na Itália e outro país & (CITTASLOW, 2011) \\
\hline 2007 & Aprox. 100 cidades & $50 \%$ delas na Itália & (MIELE, 2008) \\
\hline 2012 & Aprox. 150 cidades & $40 \%$ delas na Itália & (SEMMENS; FREEMAN, 2012) \\
\hline 2016 & 225 cidades & $30 \%$ delas na Itália & (CITTASLOW, 2016) \\
\hline
\end{tabular}

DESCRIÇÃO: O quadro acima aponta o crescimento e a evolução do Cittaslow ao longo dos anos e indica que, à medida que o movimento se expande para outros países, diminui a soberania das cidades italianas na rede.

Segundo Radstrom (2011), alguns dos membros mais recentes da rede decidiram se tornar "lentos" apenas por terem observado o progresso e o desenvolvimento da iniciativa Cittaslow em outras cidades, constatando um efeito positivo desta filosofia na ambiência urbana e na qualidade de vida dessas cidades. Esta influência, segundo a autora, criou um efeito cascata em toda a Itália (que hoje abriga mais de 70 cidades-lentas), que agora vem se repetindo no restante do mundo.

\section{O SLOW FOOD E AS REFERÊNCIAS CONCRETAS}

É inútil forçar os ritmos da vida. A arte de viver consiste em aprender a dar o devido tempo às coisas (PETRINI, 2007 In: SLOW FOOD, 2013).

O movimento Slow Food nasceu pouco mais de uma década antes do Cittaslow, em 1986, na Itália, em função de protestos liderados por Carlo Petrini para tentar impedir a instalação de uma lanchonete McDonalds no centro histórico de Roma (ao lado da Piazza di Spagna). O desejo de Petrini, no entanto, não era impedir apenas a abertura de uma lanchonete isolada, mas, sim, frear - ainda que simbolicamente - o processo de americanização da Itália.

O nome Slow Food, portanto, é uma referência crítica direta ao Fast Food, à hegemonia das chamadas empresas globais e à verdadeira conjuntura política, social, econômica e ambiental 
que está por trás dessa indústria (CARVALHO, 2015). Sua luta é contra a desertificação social, contra a banalização do lugar e dos saberes locais e contra a perda da identidade cultural.

O Slow Food dissemina uma filosofia simples, indicando que o alimento precisa ser "bom, limpo e justo" (SLOW FOOD, 2014). Isso significa que o alimento precisa ser saboroso, que deve ser cultivado de maneira consciente, com respeito à vida e ao ambiente, e que os produtores precisam receber o que é justo pelo seu trabalho. Para o Slow Food, consumidores são coprodutores, isto é, parceiros da produção, e precisam se informar e se conscientizar a respeito do ciclo produto dos alimentos - e sobre seus impactos.

O conceito a ser seguido é o da ecogastronomia ${ }^{1}$, que reconhece as relações entre "o prato e o planeta" (SLOW FOOD, 2014) e destaca os elos entre a comida, ou o modo como os alimentos são produzidos e consumidos, e a qualidade de vida das sociedades. Nesse sentido, quando se opta por "produtos da terra", experimenta-se a energia do lugar, ajudando a preservar (ou resgatar) os saberes tradicionais.

Enquanto as indústrias "despejam" alimentos homogêneos e baratos, as mãos de pequenos produtores oferecem produtos únicos, diferentes, artesanais, que não podem ser repetidos nem multiplicados ao infinito porque são feitos de gestos precisos, de saberes antigos e tradições locais, truques secretos passados ao pé do ouvido (SLOW FOOD, 2013).

Atualmente, o movimento Slow Food tem ampla repercussão, com ações em praticamente todos os cantos do planeta, através das quais o movimento contribui para a preservação da diversidade ambiental e cultural global. No entanto, apesar dessa pluralidade e abrangência, a origem italiana ainda exerce uma perceptível influência sobre seus ideais. Na Itália, grande parte da população ainda vive em centros urbanos dispersos, de pequeno ou médio porte, nos quais o sustento econômico provém, principalmente, das relações locais, do turismo cultural e da produção autóctone e artesanal, contribuindo para a fundamentação da filosofia Slow Food em função do típico e do tradicional e do caráter único do lugar.

A influência das microrregiões, ou das pequenas e médias cidades tradicionais da Itália, na formação do Slow Food, também é percebida no Cittaslow. Dessa maneira, pode-se dizer que se a referência ideológica do Cittaslow é o Slow Food, as suas referências concretas são essas pequenas comunidades típicas, de perfil histórico e/ou urbano-rural, com suas características próprias e únicas, suas ambiências calmas e agradáveis, seus vínculos territoriais fortes e vivos, sua veneração aos ritmos naturais e sua preferência por estilos de vida "lentos".

Um dos próprios fundadores do Cittaslow, Stefano Cimicchi (In: MIELE, 2008), confirma essa influência, quando afirma que as cidades medievais e renascentistas, com suas praças lotadas

1. A ecogastronomia promove a união entre a ética e o prazer da alimentação, restituindo aos alimentos sua dignidade cultural. Apoia um tipo de agricultura alternativa, menos intensiva e mais saudável e limpa (a partir do uso sustentável da biodiversidade), com base na cozinha típica e tradicional e nos valores, nos conhecimentos e nas heranças culturais das comunidades locais (SLOW FOOD, 2013). 
e funcionando como centro das relações comerciais, sociais e culturais, deram referências concretas para o direcionamento e a fundamentação do Cittaslow. Não tanto por sua tipologia e morfologia, mas, sim, pelos laços e valores que estes modelos sustentam.

Radstrom (2011) indica, ainda, que Paolo Saturnini, anter mesmo da fundação do Cittaslow, já percebia o entorno rural de Greve in Chianti, com suas famosas vinícolas, que the conferiram status e renome internacional no mercado de vinho, como um elemento vital à manutenção da identidade e da vitalidade dessa pequena cidade. Em seu relato, a autora (Ibidem, p.101) revela que:

\begin{abstract}
Several decades ago, there was a time of a very low level of employment in the area. Many people were migrating to larger cities to find work. In order to attract people back to the area, large industries were brought in. However, years later, this decision was regretted because of its negative impact on the local landscape, traditional land uses and agricultural production. Saturnini felt that the Chianti countryside was too valuable to let this happen again. The Chianti region had lost a part of its sense of place, something which was devastating to the local identity, and not always easy to reestablish. In Saturnini's words, it was a "wakeup call" for the area and for himself.
\end{abstract}

Nesse sentido, podemos concluir que o Cittaslow e o Slow Food compartilham não apenas ideologias, mas também um apreço por cidades que preservam sua história e permitem que seus habitantes se mantenham curiosos sobre seu passado; cidades ricas em teatros, praças, cafés, restaurantes e outros "lugares espirituais", de encontro e permanência; cidades que conservam suas paisagens interessantes e o charme de seus artesãos; cidades onde as pessoas reconhecem o curso das estações e o valor genuíno dos produtos, com respeito aos saberes, à saúde e aos costumes espontâneos do lugar (CITTASLOW, 2011).

\title{
A FILOSOFIA CITTASLOW
}

[...] o movimento Slow não está preocupado em fazer coisas em ritmo de cágado. Nem é uma tentativa como a do movimento luddita ${ }^{2}$, que outrora tentou arrastar todo o planeta de volta a uma utopia pré-industrial. Pelo contrário, o movimento é constituído de pessoas como você e eu, pessoas que querem viver melhor no moderno mundo da velocidade. Por isto é que a filosofia Slow pode ser resumida numa única palavra: equilíbrio. [...] viver naquilo que os músicos chamam de tempo giusto - o andamento certo (HONORÉ, 2006, p.27).

2. O luddismo ficou marcado como um movimento radical contra a tecnologia e o progresso, sobretudo em função da mecanização dos trabalhos (até então predominantemente manuais) na Inglaterra do início do século XIX, em função da Revolução Industrial. 
Quando Carl Honoré (2006) publicou seu livro, In Prise of Slow, abordando a insurgência da lentidão como um contraponto aos efeitos negativos da modernidade (CARVALHO, 2014), ele logo se tornou um ponto de contato entre os diversos movimentos ou organizações populares que se dedicavam, ainda que de modo isolado, ao ideal Slow. Foi a partir do livro de Honoré (2006) que essas iniciativas passaram a ser enquadradas em uma mesma filosofia, que acabou denominada como Slow Movement - ainda que tais iniciativas tenham se mantido autônomas, como o Slow Food e o Cittaslow.

O Slow Movement, portanto, é uma comunhão de ações que advogam a favor do devir lento, correlacionando o ideal da lentidão ao bem-estar individual e coletivo das sociedades, através da identidade, da qualidade, da sustentabilidade e outros diversos temas.

O tempo lento, presente nos discursos do Slow Movement, contrasta com o tempo rápido, com o tempo hegemônico, com o just in time, com o tempo dos mercados globais e com a efemeridade das relações de consumo. O tempo lento é um tempo que não se submete à dominação econômica e cultural, é o tempo da cultura popular, o tempo do homem comum, dos saberes vernaculares, do ócio (e do aprendizado do ócio), do bem-estar, da solidariedade e de toda poesia (Milton Santos ${ }^{3}$ In: LIMA, 2013).

O que deu sentido prático ao discurso da lentidão, em um mundo altamente tecnológico, onde a informação tem amplo alcance, as rotinas são dominadas por multitarefas e a rapidez é uma prioridade, foi o fato de as sociedades buscarem alternativas para o seu bem-estar ou para a sustentabilidade das cidades em função de estilos e ritmos de vida mais lentos.

Foi essa relação, aliada a preocupações com a preservação da identidade e da memória local, que deu base ao ideal Cittaslow, criado por Paolo Saturnini e seus colegas como uma proposta (ou um conjunto de propostas) para evitar ou reverter a decadência econômica das pequenas localidades e o subsequente esvaziamento populacional dessas áreas (RADSTROM, 2011).

No intuito de formar ambientes físicos mais calmos e menos poluídos, levando princípios ecológicos para a vida cotidiana (MIELE, 2008), o Cittaslow adotou iniciativas já introduzidas pelo Slow Food - para a preservação das tradições culinárias e do saber-fazer típico - e aplicou (ou ampliou) essas propostas ao contexto das cidades, incluindo não só os hábitos alimentares e os processos que os sustentam, mas, sim, todos os demais aspectos sociais, econômicos e ambientais que condicionam a "vida-lenta".

Cittaslow philosophy is built around the desire to provide a high quality of life for Cittaslow residents. This can involve going back to each city's roots, and looking at what made them great cities in the first place. [...]Cittaslow aims to sustain the city's own unique characteristics while also improving

3. Milton Santos fala sobre o "homem lento", um homem que sobrevive à margem do sistema capitalista, construindo formas alternativas de subsistência. Mais do que sujeitos da produção do espaço, os "homens lentos" de Santos são pessoas que "utilizam" o território. Para o autor o "tempo lento" é a "força dos fracos" e, de certo modo, reforça a importância do "lugar" (da identidade) num contexto de globalização e domínio cultural e econômico (SANTOS, 1996, p.81). 
the city so that it is a better environment in which its residents are able to enjoy living (RADSTROM, 2011, p.96).

Para Radstrom (2011), a meta principal do Cittslow é proteger as qualidades e a identidade (ou o sentido de lugar) de cada comunidade, propondo, para cada tópico, uma solução adequada e ambientalmente sustentável. A filosofia subjacente é a de identificar e apoiar os ativos de cada região, fortalecendo ou restabelecendo os vínculos com o território e com a localização que tem sido historicamente a base para a vida em comunidade. Desse modo, o caráter único do lugar se torna a base para a sustentabilidade econômica e também para a preservação cultural e ambiental local, constituindo a essência filosófica da proposta.

A categoria Cittaslow, nesse sentido, é tanto um selo (de qualidade), quanto uma marca de distinção, que indica para turistas, residentes e investidores um compromisso com a qualidade de vida, com a cultura, com a biodiversidade e até mesmo com a sustentabilidade. $\mathrm{O}$ que se espera é uma comunidade com identidade própria, facilmente reconhecida por quem chega e profundamente sentida por quem a vivencia.

A exploração da marca (o city branding), no caso do Cittaslow, é utilizada no sentido de ajudar na divulgação dos ideais do movimento, favorecendo a sua implantação e a sua disseminação. Miele (2008) ressalta, ainda, que a associação de uma cidade ao Cittaslow não impede a sua participação em outras redes ou campanhas de marketing territoral. Ao contrário, muitas das cidades que recebem o título de cidade-lenta já possuem algum outro tipo de marca (como a cidade do vinho, a cidade das rosas, a cidade do couro e etc) que valoriza suas características imateriais, servindo de base para o turismo e as demais atividades econômicas locais.

Para Mayer e Knox (2006) a filosofia Cittaslow se resume a elevar a qualidade de vida de uma comunidade, objetivando sua sustentabilidade social, econômica e ambiental. Nesse sentido, o Cittaslow busca apresentar diretrizes para cada um desses objetivos, convergindo suas ações para a valorização do território, da ambiência, da cultura e da natureza do lugar.

Paolo Saturnini (In: MIELE, 2008, p.136), nos ajuda a concluir, ao afirmar que:

Slow Cities were not born as a conservation movement, but, rather, as a movement that in the wake of modernization and globalization asks itself about how to transfer "cities" in a globalized world without making them lose their soul in the journey.

\section{O CITTASLOW INTERNATIONAL}

Being "slow" doesn't mean arriving late. On the contrary, it means using new technologies to make towns and cities ideal places to live in (Stefano Cimicchi In: MIELE, 2008

O conceito Cittaslow representa tanto a proposta das cidades-lentas, quanto a rede formada por cidades que aderem ao movimento - intitulada como "rede internacional de cidades do bem-viver" (ou "de cidades onde viver é fácil", segundo a tradução oficial). A cidade-lenta 
propriamente dita, portanto, é cidade que integra a rede Cittaslow, que opta por seguir a filosofia do movimento, aplicando suas diretrizes, e que se torna oficialmente habilitada a fazer uso de sua marca (e logotipo).

Imagem 01: Logotipo oficial do Cittaslow.
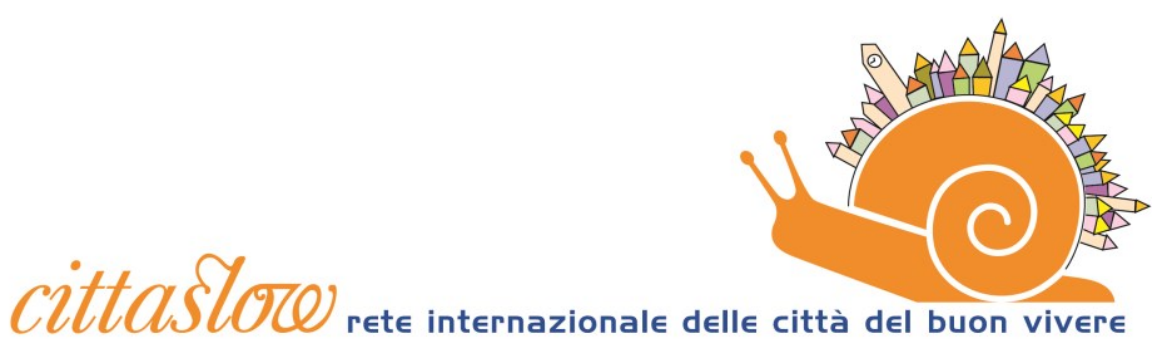

DESCRIÇÃO: O Cittaslow pegou emprestado o símbolo do Slow Food - que é o caracol (ou lesma) -, deu a ele a cor laranja e colocou em suas costas uma coroa com edificações históricas e modernas misturadas (CITTASLOW, 2014).

A "cidade do bem-viver" enunciada pelo movimento é a própria cidade-lenta. Para Giorgio Oliveti (2016), o "bem-viver", ainda que seja uma categoria subjetiva, individual e pessoal, se refere à oportunidade de desfrutar de soluções e serviços que permitam aos cidadãos viver a sua cidade de maneira fácil e agradável. Isso significa, no contexto do Cittaslow, priorizar a qualidade do ambiente e de seus recursos, canalizando os ideais de preservação e o uso de novas tecnologias para o bem-estar de seus habitantes.

Institucionalmente, o movimento é dirigido por uma organização não governamental, com o nome de "Cittaslow International". É o Cittaslow International que recebe as candidaturas e decide a adesão de novas cidades à rede, que cuida das ações de divulgação e dos eventos de maior porte, sejam eles nacionais ou internacionais, e que indica novas diretrizes e reavalia os rumos gerais do movimento. Sua estrutura organizacional inclui um comitê de coordenação, que toma as decisões, um comitê científico, que atua no âmbito das ideias, e um secretariado, que lida com toda a parte operacional (CITTASLOW, 2011).

Além do Cittaslow International, existe também a figura do "Cittaslow Nacional", com papel mais ou menos decisivo, dependendo do modo como cada país o estrutura. As entidades nacionais, no entanto, são opcionais e atuam apenas de maneira auxiliar, sem atribuições oficiais, em países que possuem três ou mais cidades-lentas. Quem tem a autonomia para definir a titulação ou desvinculação de uma cidade-lenta, além de outras questões gerais que influenciam a rede, é o Cittaslow International.

Giorgio Oliveti esclarece, ainda, que apesar de sua influência ideológica, o Cittaslow não tem nenhum vínculo institucional com o Slow Food e faz uma ressalva importante, ao destacar pelo

4. Pier Giorgio Oliveti é o atual Diretor do Cittaslow International e concedeu algumas entrevistas ao autor durante suas pesquisas na Itália, entre os meses de abril e julho de 2016. 
menos duas grandes distinções entre as iniciativas. Primeiro, porque o Cittaslow apresenta uma proposta mais ampla e complexa, que envolve a cidade, a sociedade e a administração pública local, e segundo porque o Cittaslow é uma iniciativa privada que lida diretamente com entidades públicas, enquanto o Slow Food é uma iniciativa privada que lida com associações privadas. E isso, segundo Giorgio Oliveti, faz toda a diferença, uma vez que a aplicação das propostas do Cittaslow depende do empenho, da compreensão e da vontade política local (ou seja, do interesse público), enquanto o Slow Food pode (ou não) ser adotado segundo os ideais e os objetivos de cada empreendedor.

\section{POLÍTICAS E ESTRAÉGIAS PARA O DESENVOLVIMENTO SUSTENTÁVEL}

Unfortunately, the interpretation of Cittaslow as countering the fast pace of life is not necessarily accurate. The slow in Cittaslow concerns the idea of taking the time for quality. However, residents of Cittaslow do not necessarily have a slower pace of life. Many writers only interpret the word slow based upon the common English use of the word, remaining ignorant of the original intention, which is based upon the Italian cultural interpretation inherent to Slow Food and goes far beyond a simple notion of speed. It represents a higher quality of life and taking the time to achieve and appreciate this quality (RADSTROM, 2011, p.95).

A cidade-lenta é, em síntese, uma cidade real, com características sociais, culturais e espaciais que se adequam à filosofia Slow. A imagem é de um lugar onde se respeita o passado, onde o homem ainda é o protagonista da sucessão lenta e saudável das estações, onde se incentiva o respeito pela vida e pelo ambiente, e onde aspectos como o prazer, a memória, a qualidade, a autenticidade e a convivialidade, entre outros, são valorizados. Ou seja, a cidade-lenta parece ser lenta mesmo antes de ser oficialmente denominada como tal.

Para se candidatar ao posto de cidade-lenta, a cidade interessada não pode ter mais do que 50 mil habitantes, precisa pagar uma taxa ao Cittaslow International, que varia de acordo com o porte populacional de cada município, e precisa atender a uma determinada porcentagem de critérios dispostos em uma lista de pré-requisitos, concordando em seguir tanto as diretrizes do Cittaslow, quanto do Slow Food (CITTASLOW, 2011).

É a administração municipal que se responsabiliza por avaliar o perfil de sua cidade frente aos requisitos da cidade-lenta, optando por realizar (ou não) sua candidatura. Uma vez candidata, a cidade assume um compromisso formal com as metas do movimento. Contudo, como tais metas incluem questões do cotidiano e do estilo de vida de cada comunidade, é preciso que a população local tome conhecimento e se sensibilize com os processos.

Miele (2008) descreve esses critérios como um código de conduta tangível e verificável, que visa promover o melhor conhecimento do passado e o aproveitamento das possibilidades do presente e do futuro no desenvolvimento da cidade-lenta. Os critérios estão dispostos no "Cittaslow Charter", uma espécie de estatuto ou cartilha disponível no site oficial do Cittaslow, 
com metas e compromissos que devem ser assumidos por cidades que desejam ser "lentas" o documento serve de parâmetro tanto para cidades candidatas, quanto para cidades que já receberam a titulação oficial.

Dentre os principais requisitos de sua cartilha (CITTASLOW, 2014), denominados de "requisitos para a excelência ${ }^{5 " \prime}$, encontram-se:

- políticas de energia e planejamento ambiental;

- políticas de infraestrutura;

- políticas de valores urbanos (que envolve a qualidade de vida e do ambiente);

- políticas para a agricultura, o turismo e a produção autóctone;

- políticas de hospitalidade, para sensibilização e formação da população no intuito de receber e instruir os visitantes;

- políticas para manter a coesão social (para a aceitação e o envolvimento comunitário);

- e políticas para a participação em parecerias, para difusão e a divulgação da filosofia Cittaslow pelo mundo.

O estatuto (ou cartilha) do Cittaslow, no entanto, é flexivél e pode ser ajustado de acordo com as particularidades de cada lugar. Há um escopo mínimo fixo que deve ser atendido, para dar certa unicidade às cidades-lentas, ao qual se pode adicionar outras diretrizes individualizadas e contextualizadas, dando ao município a possibilidade de propor, à sua maneira, novos modos de implantar ou de lidar com a cartilha Cittaslow - o que contribui para uma reformulação constante de seus princípios (MIELE, 2008).

Ecologia e sustentabilidade são itens elementares na agenda do Cittaslow (2014). A política de planejamento ambiental (energy and environmental policy, no original) é o primeiro requisito para a "excelência" da cidade-lenta e sua proposta envolve questões como:

- a melhoria da qualidade do ar e da água;

- a disponibilização de água potável para residentes;

- a separação e a destinação correta de dejetos e resíduos sólidos;

- a compostagem industrial e residencial;

- a purificação do esgoto coletado;

- a eficiência energética de prédios e sistemas públicos;

- a geração de energia a partir de fontes renováveis;

5. A Cartilha do Cittaslow, em seu "Anexo C", dispõe sobre Requirements for Excellence, uma lista com tópicos abrangentes, com ações específicas para cada tema (CITTASLOW, 2014). Segundo Giorgio Oliveti (2016), os critérios iniciais foram revistos em 2006, em função das contribuições trazidas pela entrada de outros aportes culturais na rede. 
- a redução da poluição visual, sonora e luminosa das cidades, para dar mais valor às suas características históricas;

- maior controle do consumo de energia elétrica;

- e ainda outras ações para a conservação da biodiversidade e o manejo adequado dos recursos naturais locais.

O Cittaslow inclui em seu escopo, portanto, metas e propostas que podem ser encontradas em qualquer projeto de "cidade sustentável", diferenciando-se deste apenas por sua dedicação em tentar conciliar a introdução de práticas e tecnologias ecoeficientes, com a proteção ou a valorização da diversidade cultural e ambiental de cada lugar (CARVALHO, 2015).

As casas e edifícios ecoeficientes, a redução de áreas impermeáveis dentro da malha urbana, o incentivo ao uso da bicicleta, a priorização do pedestre, favorecendo o ato de caminhar (walkability), e a permacultura, entre outros, são aspectos de uma cidade sustentável que também se encontram no escopo do Cittaslow.

Seu objetivo é fazer com que as pessoas reconquistem as cidades, tirando-as das mãos das grandes empresas, de empreendedores imobiliários, das fábricas e dos carros poluentes. Para isso, o Cittaslow valoriza o patrimônio urbano e arquitetônico local, evitando a construção de novos prédios, e combate a poluição, incentivando a formação de ambientes calmos e saudáveis, a partir da multiplicação de áreas verdes e da adoção de práticas menos poluentes. A cidade do Cittaslow é, sobretudo, uma cidade compartilhada, acolhedora e cheia de lugares agradáveis, onde encontros são possíveis e comuns. Uma cidade que, sem abrir mão do seu caráter único, tenta ser sustentável através da valorização da vida (CARVALHO, 2014).

O Cittaslow, no entanto, não deve ser confundido com as propostas para cidades sustentáveis que vêm sendo comercialmente disseminadas no século XXI como a única alternativa para a "salvação" da humanidade. Tais propostas, apesar de partilhar o apelo ecológico e de incluir preceitos eco-eficientes em seus escopos, têm se demonstrado mais um meio de comercializar produtos humanos a partir do selo ambiental, do que uma forma de empregar, com justiça e equidade, a sustentabilidade às cidades.

\section{O CITTASLOW E O URBANISMO ECOLÓGICO}

Nature in the city is far more than trees and gardens, and weeds in sidewalk cracks and vacant lots. It is the air we breathe, the earth we stand on, the water we drink and excrete, and the organisms with which we share our habitat... It is the consequence of a complex interaction between the multiple purposes and activities of human beings and other living creatures and of the natural processes that govern the transfer of energy, the movement of air, the erosion of the earth, and the hydrologic cycle. The city is part of nature (SPIRN, 1984, p.04). 
O biólogo naturalista alemão Ernst Heackel (1866) foi o primeiro a empregar, ainda no século XIX, o termo "ecologia" para destacar a importância de compreender o "lugar onde se vive", nos estudos sobre os organismos vivos. Ao contrapor a visão antropocêntrica vigente, com uma proposta de estudo de viés biocêntrico, Heackel deu à ecologia o papel de ciência que estuda as condições ambientais da existência (FRANCO, 1997, p.93), incluindo os seres vivos, seu meio e os processos que os moldam em um mesmo campo de investigação.

Desde Heackel até hoje foram apresentadas diversas contribuições para o estudo da dinâmica dos ecossistemas. A ecologia evoluiu ao mesmo tempo em que foi tomada como fundamento para outros importantes campos de conhecimento, como urbanismo, arquitetura, sociologia e antropologia, entre outras disciplinas ligadas a relação dos homens com seu meio.

A maior conscientização das sociedades acerca dos preceitos ecologistas e ambientalistas, no entanto, só ocorreu na segunda metade do século XX, quando os impactos da ação humana sobre os ecossistemas naturais do planeta se tornaram mais perceptíveis. Para Rogers (2001), os homens só puderam ter maior consciência sobre suas ações, porque passaram a observar e compreender - seu mundo de maneira global. Conforme o autor (Ibidem, p.03):

Em 1957, o primeiro satélite era lançado na órbita da Terra. Isso nos oferecia uma posição privilegiada, a partir da qual podíamos olhar para nós mesmos e assinalar o começo de uma nova consciência global, uma mudança dramática no nosso relacionamento com o planeta. Vista do espaço, a beleza de nossa biosfera é fantástica - mas é fantástica também a sua fragilidade. As manchas de poluição, as feridas do desmatamento, as cicatrizes da industrialização e a expansão caótica de nossas cidades são evidências de que, na nossa busca por riqueza, estamos sistematicamente espoliando todos os aspectos do sistema de apoio à vida do planeta.

Essa noção global deu enorme impulso aos movimentos ecologistas e ambientalistas, que, em um período de 50 anos, deixaram de lutar somente pela proteção de espécies ameaçadas ou áreas selvagens isoladas ${ }^{7}$, para lutar pela manutenção da integridade ambiental do planeta e pelas condições de sobrevivência da própria espécie humana.

A perspectiva de um "urbanismo ecológico", apesar de fazer parte do imaginário social e de já haver sido introduzida anteriormente, a partir de estudos e análises que sugeriam a ecologia como alternativa aos problemas das cidades e como inspiração para um urbanismo inclusivo e sensível ao ambiente, teve seu maior destaque no ínicio do século XXI.

Embuídos em constituir e oferecer base fundamental suficiente para estabelecer a temática do urbanismo ecológico como prática (re)conhecida e adotada em todo o mundo, profissionais e

6. O termo "eco" deriva do grego "oikos", que significa o lugar, a casa ou o ambiente onde se vive.

7. O Parque Nacional de Yellowstone, criado em 1872, nos Estados Unidos, é uma das primeiras vitórias da causa ecologista no mundo. No entanto, apesar de sua importância, a proteção desta área selvagem representa uma ação ainda muito distante da almejada visão biocêntrica da vida. 
estudantes com trabalhos reconhecidos em diversas áreas de conhecimento, se reuniram em uma conferência internacional, em 2009, organizada pela Graduate School of Design (GSD) da Universidade de Harvard, em Cambridge, nos Estados Unidos, para se debater a ecologia e a sustentabilidade em escalas urbanas, no intuito de esclarecer o que é, quais os rumos e o que pode significar o urbanismo ecológico para as futuras gerações (HERZOG, 2009).

Para Mostafavi e Doherty (2014), responsáveis pela edição do livro "Ecological Urbanism", com 656 páginas, que compilou os trabalhos e as análises realizadas na conferência, o urbanismo ecológico representa uma oportunidade "de se arguir sobre a ética e a estética das cidades", conduzindo a respostas que servem tanto aos problemas atuais, quanto aos problemas futuros - associados às mudanças climáticas e aos impactos da ação humana no ambiente.

[...] the practice of ecological urbanism as a means to achieve cities that are more life-sustaining and more resilient, and less costly to build and maintain (SPIRN, 2011, p.01).

O urbanismo ecológico, portanto, está ligado à sustentabilidade das cidades, à eficiência e à qualidade de seus serviços e de sua infraestrutura, defendendo abordagens mais holísticas na produção e na gestão dos espaços urbanos. Para Spirn (2011), a filosofia que embasa o ideal do urbanismo ecológico já está presente em nossas sociedades há tempos, uma vez que desde os gregos antigos, já existiam análises capazes de descrever os efeitos do ar, das águas e dos lugares na saúde dos indivíduos e das comunidades.

De modo semelhante, o famoso arquiteto romano Vitruvio estava ciente de que as vias e o arranjo de edificações poderiam ser influenciados pela orientação solar e por ventos sazonais, e que a correta utilização desses fatores ajudaria a construir de modo econômico, lógico e belo (Rem Koolhaas In: MOSTAFAVI; DOHERTY, 2014).

Nesse sentido, o que pode justificar uma maior disseminação do urbanismo ecológico após a conferência de 2009, em Harvard, é justamente o fato de as sociedades estarem mais cientes dos impactos e das consequências de suas ações, fornecendo abertura às novas alternativas, como o Cittaslow e o Slow Food, por exemplo.

\section{CONSIDERAÇÕES FINAIS}

Se continuarmos nesse ritmo, o culto da velocidade só poderá piorar. Quando todo mundo opta pela alternativa mais rápida, a vantagem de andar depressa desaparece, obrigando todos a ir ainda mais depressa (HONORÉ, 2006, p.22).

O Cittaslow constitui, portanto, uma marca de qualidade para as pequenas comunidades ou cidades históricas e tradicionais. Sua filosofia e suas políticas, ainda que sejam constituídas de metas capazes de obter sucesso nas grandes cidades, possuem maior eficiência quando são 
implementadas na pequena escala, aproveitando-se das oportunidades locais para dar um direcionamento sustentável ao desenvolvimento urbano.

O Cittaslow, no entanto, não está fundamentado apenas em função do planejamento urbano ou da sustentabilidade ambiental. É um conceito mais amplo, que abrange simultaneamente diversos aspectos do desenvolvimento local. Dessa maneira, o Cittasloe se aproxima do ideal do urbanismo ecológico quando argumenta a favor de cidades vivas e espaços multifuncionais, dinâmicos e interconectados, onde as pessoas, o urbano e a natureza compõem um único e harmonioso ecossistema.

Sua proposta sugere, tal como Jane Jacobs (2000), uma maior atenção à escala e às demandas humanas, direcionando as políticas públicas para o bem-estar ou para o "bem-viver" de suas comunidades. Em sua cartilha a identidade local assume um papel fundamental, conciliando a vitalidade e o desenvolvimento econômico, com a proteção dos valores locais. A valorização da marca e do caráter único da cidade-lenta é o que dá suporte às demais ações e objetivos do Cittaslow, contribuindo também para as relações entre microrregiões.

O Cittaslow demonstra, com isso, que para criar cidades sustentáveis é preciso considerar também os modos de vida. Para isso, o espaço urbano deve ser capaz de facilitar as rotinas e as experiências sociais, considerando (além do respeito pelo meio) o bem-estar, a justiça e os valores culturais em sua formação. Enquanto a cidade sustentável busca promover qualidade de vida a partir da sustentabilidade, a cidade-lenta tenta ser sustentável através da valorização da vida, considerando sempre cidades (e relacionamentos) reais - sem cari na utopia de tentar propor cidades ou sociedades ideais.

Segundo Giorgio Oliveti, o Cittaslow não veio para renegar as tecnologias. Não representa o retrocesso das cidades. Não quer combater o desenvolvimento da humanidade, nem nos jogar de volta à idade média. As cidades medievais são o modelo porque apresentam condições espaciais e de interação social que favorecem a filosofia do Cittaslow. Mas com a expansão do Cittaslow pelo mundo, novas formas e novos conceitos de vida lenta estão surgindo.

A cidade-lenta, portanto, se espelha na smart city, mas, de outro modo, busca ser uma "smartcity-low-cost", contrapondo o ideal de cidade inteligente e sustentável do momento - que ao fazer uso das tecnologias e aumentar a eficiência da fábrica urbana, também consome parcela significativa de recursos. O Cittaslow, por outro lado, busca introduzir tecnologias e promover as condições para que essas tecnologias possam ser inseridas em cidades que já funcionam, de certa maneira, com baixo impacto ambiental. São lugares naturalmente com pouca poluição sonora ou visual, mais próximos da natureza e já com certa vocação para a "vida-lenta".

\section{REFERÊNCIAS BIBLIOGRÁFICAS}

CALZATI, V.; SALVO, P. Le strategie per uma valorizzazione sostenibile del território. FrancoAngeli: Milano, 2012. 
CARVALHO, Rubens M. R. "Lentidão", território e bem-estar: o movimento da cidade lenta e a sustentabilidade do lugar. Periódico Técnico e Científico Cidades Verdes, No.02, 2014, pp. 73-89.

CARVALHO, Rubens M. R. Cittaslow: vida lenta e sustentabilidade nas cidades do bem viver. Periódico Técnico e Científico Cidades Verdes, Vol. 03, No.07, 2015, pp. 37-52.

CITTASLOW. Cittaslow Charter. 2014. Disponível em: <http://www.cittaslow.org/>. Acesso em: 30 nov. 2014.

CITTASLOW. Cittaslow Network. 2015. Disponível em: <http://www.cittaslow.org/>. Acesso em: 14 abr. 2015.

CITTASLOW. Cittaslow List. 2016. Disponível em: <http://www.cittaslow.org/>. Acesso em: 15 ago. 2016.

CITTASLOW. Rete Internazionale delle Città del buon vivere (Livreto de divulgação). Milano: Cittaslow International, fev. 2014.

FRANCO, Maria de Assunção Ribeiro. Desenho Ambiental: uma introdução à arquitetura da paisagem como paradigma ecológico. São Paulo: Annablume/FAPESP, 1997.

HARVARD. David Rockefeller Center for Latin American Studies - Brazil. Ecological Urbanism. 2016. Disponível em: <http://brazil.drclas.harvard.edu/ecological-urbanism>. Acesso em: 20 ago. 2016.

HERZOG, Cecília Polacow. Cidades para Todos: (re)aprendendo a conviver com a Natureza. São Paulo: Editora Mauad, 2013. $311 \mathrm{p}$.

HERZOG, Cecilia P. Urbanismo ecológico. Tema de conferência internacional na Universidade de Harvard. Arquitextos, São Paulo, ano 10, n. 109.00, Vitruvius, 2009.

HINCAPIÉ, Laura S. Así viven en Pijao (Quindío), el pueblo 'sin prisa' de Latinoamérica. El Tiempo. Bogotá, 2014. Disponível em: <http://eltiempo.com/colombia>. Acesso em: 16 abr. 2015.

HONORÉ, Carl. Devagar: como um movimento mundial está desafiando o culto da velocidade (In Praise of Slow). Rio de Janeiro: Record, 2006.

JACOBS, Jane. Morte e vida de grandes cidades. São Paulo: Martins Fontes, 2000.

KNOX, Paul L. Creating Ordinary Places: Slow Cities in a Fast World. Journal of Urban Design, Vol. 10, No. 1, 2005, pp. 1-11.

LIMA, Elias Lopes. O lugar do sujeito em "a natureza do espaço", de Milton Santos. Revista Geografia, Vol. 3, No. 2, 2013, pp. 1-8.

MAYER, Heike; KNOX, Paul. Slow Cities: Sustainable Places in a Fast World. Journal of Urban Affairs, Vol. 28, No. 4, 2006, pp. 321-334.

MAYER, Heike; KNOX, Paul. Small-Town Sustainability: Prospects in the Second Modernity. European Planning Studies, Vol. 18, No. 10, 2010, pp. 1545-1565. 
MIELE, Mara. Cittaslow: Producing Slowness against the Fast Life. Space and Polity, Vol. 12, No. 1, 2008, pp. 135156.

MOSTAFAVI, Mohsen E DOHERTY, Gareth. Urbanismo ecológico. São Paulo: Gustavo Gili, 2014.

PEPPER, David. Ambientalismo Moderno. Instituto Piaget: Lisboa, 1996.

RADSTROM, Susan. Place-Sustaining Framework for Local Urban Identity: an Introduction and History of Cittaslow. Italian Journal of Planning Practice (IJPP), Vol. I, No. 3, 2011, p. 90-113.

Richard. Cidades para um pequeno planeta. Barcelona: Gustavo Gilli, 2001.

SANTOS, Milton. A natureza do espaço: técnica e tempo, razão e emoção. São Paulo: HUCITEC, 1996, 308 p.

SEMMENS, Jaime e FREEMAN, Claire. The Value of Cittaslow as an Approach to Local Sustainable Development: A New Zealand Perspective. International Planning Studies. Vol. 17, No. 4, 2001, pp. 353-375.

SLOW FOOD (site oficial). Our history. Site Internacional, 2014. Disponível em: <http://www.slowfood.com/>. Acesso em: 20 maio 2014.

SLOW FOOD. O Movimento Slow Food (Textos e Notícias). 2013. Disponível em: <http://www.slowfoodbrasil.com/>. Acesso em: 25 mai. 2014.

SPIRN, Anne Whiston. Ecological urbanism: a framework for the design of resilient cities. (2011). In: PICKETT, S. T. A., CADENASSO, M. L. e MCGRATH, B. Resilience in Ecology and Urban Design. Springer: USA, 2013.

SPIRN, Anne Whiston. The Granite Garden. New York: Basic Books, 1984.

UNICEF. Um mundo urbano (Unicef). 2012. Disponível em: <http://www.unicef.org/sowc2012/urbanmap/>. Acesso em: 10 out. 2015.

VEIGA, José Eli. Cidades Imaginárias: o Brasil é menos urbano do que se calcula. São Paulo: Editora Autores Associados, 2002. 